\title{
Gestão Ambiental: Uma Avaliação Crítica na Indústria de Fumo Brasileira O Caso Souza Cruz
}

\section{Resumo}

$\mathrm{O}$ artigo apresenta uma pesquisa sobre as práticas de gestão ambiental da maior empresa do setor de tabaco no Brasil, a Souza Cruz. São apresentados dados extraídos de seus Relatórios Anuais, bem como de outras fontes secundárias, sendo feita uma análise crítica dos mesmos com a perspectiva de apontar pontos fortes e fracos de suas práticas de sustentabilidade.

\begin{abstract}
This paper presents the results of a research about environmental management practices observed in the most important tobacco company in Brazil, Souza Cruz. Data extracted from the company's annual reports and other secondary sources are presented and criticezed, indicating strengths and weaknesses of its sustainability practices.
\end{abstract}

Palavras-Chave: Balanço Social, Gestão Ambiental, Controle de Emissão de Gases, Economia de Água, Controle de Efluentes.

\section{Sumário}

\section{Introdução}

1- A Indústria de Fumo no Brasil

2- A Gestão Ambiental na Souza Cruz

3- Considerações Finais

\section{Introdução}

Este artigo visa analisar a aplicação de conceitos de Gestão Ambiental dentro da mais importante empresa do setor de tabaco no Brasil, a Companhia Souza Cruz, a partir de dados de seus balanços sociais.

Essa empresa, à parte estar inserida num segmento econômico cada vez mais regulado e restringido por diversos atos governamentais, vem implantando uma série de medidas de prevenção e contenção de danos potenciais ao meio-ambiente que, eventualmente, poderiam ser replicadas em outras empresas e setores da economia, visando adequá-los aos conceitos de Responsabilidade Social Corporativa e Desenvolvimento Sustentável.

A metodologia utilizada para este estudo de caso é a pesquisa de dados secundários, provenientes basicamente dos Balanços Sociais da empresa, de conhecimento público. A pesquisa de dados primários, com a visita às diversas instalações da empresa, não está no escopo deste trabalho.

Espera-se que a abordagem crítica deste trabalho propicie insights não somente a estudiosos da questão ambiental no Brasil, mas também aponte possíveis áreas de melhoria na gestão ambiental de empresas de diversos segmentos econômicos do país.

\section{1- A Indústria de Fumo no Brasil}

Segundo dados do Ministério da Agricultura, em 2003 a produção de fumo no Brasil alcan-

\footnotetext{
${ }^{1}$ Mestre em Administração pela Fundação Getúlio Vargas, São Paulo. Coordenador e professor do curso de Administração das Faculdades Integradas "Campos Salles".
} 
çou 648,5 mil toneladas em 389,2 mil hectares de cultivo. A produtividade foi assim de 1,66 ton/ha, ligeiramente abaixo da média da década, de 1,68 ton/ha. A região sul concentra $96 \%$ da produção brasileira, em função das exigências climáticas e de solo da planta. Segundo informações da Companhia Souza Cruz, a estrutura da maior parte das propriedades que cultivam fumo pode ser caracterizada como "minifúndios", to- talizando cerca de 45 mil pequenos produtores familiares.

No que tange ao consumo do principal produto da indústria, os cigarros, o Brasil segue como o sexto principal mercado do mundo, como mostra a Tabela 1 a seguir.

Tabela 1. Consumo aparente de cigarros no mundo - principais mercados

(Em milhões de unidades)

\begin{tabular}{|c|c|c|}
\hline Posição & País & Volume \\
\hline \hline 1 & China & 1.655 \\
\hline 2 & EUA & 519 \\
\hline 3 & Japão & 319 \\
\hline 4 & Rússia & 231 \\
\hline 5 & Indonésia & 197 \\
\hline 6 & Brasil & 105 \\
\hline
\end{tabular}

Fonte: Liemt, Gijsbert van. The world tobacco industry: Trends and prospects. Disponível em http://www.ilo.org/public/ english/dialogue/sector/papers. Acesso em: 20 set. 2007.

No entanto, saliente-se que a indústria estima que aproximadamente $1 / 3$ do mercado brasileiro seja ocupado hoje por produtos ilegais, sejam eles falsificados, produto de roubo ou contrabandeados.

O fato do país ser um grande consumidor desse produto põe em relevo a necessidade de que a indústria siga padrões ambientais que sejam adequados ao conceito de Desenvolvimento Sustentável, já que estão mobilizados recursos naturais - terra, cultivares e humanos - trabalhadores agrícolas e industriais - em quantidade expressiva. Mais que isso, o fato dessa indústria gerar controvérsias, impõe que ela se comporte com altos padrões de Responsabilidade Social Corporativa, sob pena de ser questionada sua própria existência.

Neste pequeno trabalho, tentar-se-á verificar a adequação e a eficácia dos programas de gestão ambiental de uma empresa que domina $75 \%$ desse mercado, de uma forma crítica.

Ressalte-se que a totalidade das informações acerca do programa de gestão ambiental da empresa é pública, constando de seu RELATÓRIO SOCIAL 2003. 


\section{2- A Gestão Ambiental na Souza Cruz}

A empresa tem aplicado o conceito de Responsabilidade Social Corporativa de uma forma abrangente: patrocina o Instituto Souza Cruz, o qual possui como foco a educação de jovens; possui um programa interno, chamado de "Jornada para o Futuro", que tem como eixo condutor a "sustentabilidade econômica, social, ambiental, ética e na gestão dos talentos humanos".

Dentre as iniciativas no âmbito da Gestão Ambiental, foram implantados indicadores referentes às seguintes áreas e aspectos de sua atuação:

- Energia;

- Materiais;

- Água;

- Emissões, Efluentes e Rejeitos;

- Transporte;

- Fornecedores;

- Produtos e Serviços;

- Uso da terra e biodiversidade;

- Legislação ambiental e social.

A seguir, serão discutidos os dados e informações apresentados pela empresa, que teve seu Balanço Social auditado pelo Bureau Veritas Quality International.

No aspecto energia, de 2002 a 2003 a empresa apresentou um aumento na energia consumida, medida em gigajoules: de 1.116 .670 para 1.951.865 gigajoules. Quando se analisa o consumo médio por milhão de cigarros produzidos, observa-se um incremento de quase $100 \%$, de 6,31 para 11,94 gigajoules por milhão de cigarros. A empresa explica que, de 2002 a 2003 houve um recálculo no fator técnico que converte o consumo de lenha em energia, que estava subestimado anteriormente a essa correção; adicionalmente, uma nova unidade fabril entrou em operação.

No aspecto consumo de materiais, o principal dado apresentado é o da redução da utilização de agrotóxicos nas lavouras de fumo. De 1993 a 2003 , houve uma redução de $6,6 \mathrm{~kg} /$ ha para 1,1 $\mathrm{kg} / \mathrm{ha}$ de uso de ingredientes ativos, o que diminui riscos à saúde tanto de trabalhadores rurais quanto dos próprios fumantes, já que uma parte dos defensivos utilizados pode permanecer no tabaco mesmo após seu processamento. A utilização de "substâncias perigosas" no ambiente fabril está sendo controlada e revista, porém não houve o disclosure de quais substâncias seriam estas.

No quesito relativo ao uso de água, de 2002 a 2003 houve um aumento de $3,40 \mathrm{~m}^{3}$ /milhão de cigarros produzidos para $3,54 \mathrm{~m}^{3}$ /milhão de cigarros produzidos. $\mathrm{O}$ indicador equivalente, que substitui milhão de cigarros produzidos por tonelada métrica de fumo processado, também apresentou incremento, passando de 3,22 para 3,60. Apesar disso, a empresa reduziu seu consumo total de água em 3,8\% frente ao ano anterior - quando já havia sido obtida uma redução anual da ordem de $15,8 \%$. Tais indicadores mostram que processos fabris mais água-demandantes foram sustentados por um programa extra-produtivo de redução de consumo - nas áreas de limpeza e higiene, por exemplo. A empresa sustenta que a operação brasileira é considerada benchmark nesse quesito dentro do grupo BAT.

$\mathrm{Na}$ área de emissões, efluentes e rejeitos, os indicadores apontam que, de 2002 a 2003:

- as emissões de $\mathrm{CO}^{2}$ tiveram um incremento de $16 \%$, passando de 120,596 para 140,634 toneladas métricas equivalentes de $\mathrm{CO}^{2}$ - em função da entrada em operação da nova fábrica;

- a geração de rejeitos aumentou $11 \%$, sendo que aproximadamente $6 \%$ do total de 14,923 toneladas métricas (2003) são enviados a aterros; o restante, $94 \%$, são reciclados ou reutilizados de alguma forma;

- do esgoto, $94 \%$ foram tratados em ambos os anos; $6 \%$ foram despejados sem tratamento na rede pública.

Há de se ressaltar o alto índice de reciclagem obtido pela companhia.

No quesito transporte, a empresa divulga uma redução das viagens de negócios, fazendo com que a emissão de $\mathrm{CO}^{2}$ passasse de 7,880 toneladas métricas para 3,315 toneladas métricas de emissões equivalentes de $\mathrm{CO}^{2}$ - uma redução da ordem de $58 \%$ em um ano. Ainda nesse quesito, a entrega dos produtos produziu em 2003 a emissão de 14,452 toneladas métricas de emis- 
sões equivalentes de $\mathrm{CO}^{2}$, ante 11,298 toneladas em 2002, observando-se, portanto, um aumento da ordem de $28 \%$. A empresa faz constar que sua política deliberada para o transporte de seus produtos é sempre analisar a viabilidade de utilização de fontes de energia mais limpas, bem como efetuar uma manutenção adequada de sua frota de veículos, a fim de que esses mantenham níveis adequados de emissão de gases poluentes. Uma evidência é o fato de, dos 40 milhões de quilômetros/ano rodados pela frota de venda e de entrega da Souza Cruz, os veículos a gás representem $16 \%$, ou seja, 6,5 milhões de quilômetros/ano.

No tocante a fornecedores, a totalidade dos mesmos passa por uma certificação com critérios internos ao grupo BAT mundialmente. Tais critérios não foram divulgados no relatório.

Com relação aos produtos e serviços, uma diretriz interna determina que a empresa deve documentar todos os possíveis impactos ambientais, de saúde e de segurança detectados em seus produtos e serviços.

Com relação ao uso da terra e a biodiversidade, a empresa informa possuir um total de 8,337 ha, sendo 2,679 deles utilizados ou modificados para fins produtivos. Também informa que toda madeira utilizada na secagem das folhas de tabaco, e a madeira utilizada em galpões, é retirada de forma sustentável e gerenciada. Textualmente,

A Souza Cruz gera energia por meio da queima de biomassa (lenha), o que produz gás carbônico. A lenha utilizada nesse processo é proveniente de reflorestamento próprio. A área reflorestada é capaz de absorver todo o gás carbônico gerado por essa queima, mantendo o sistema em equilíbrio. $\mathrm{O}$ número de árvores plantadas pela empresa, em áreas reflorestadas ou de preservação que gerencia, é superior à quantidade necessária para impedir a elevação do efeito estufa. Sendo assim, a companhia não considera necessário desenvolver estudos específicos para seqüestro de carbono.(SOUZA CRUZ, 2003:60).

Finalmente, a política da empresa com relação à legislação sócio-ambiental é a de, quando possível, superar as conformidades legais. No ano de 2002 apresentou uma total conformidade com a lei, e no ano de 2003 foi multada pelo Ibama em função da ausência de licença para funcionamento de um posto de abastecimento de combustível.

No Quadro 1 a seguir, é esboçado um resumo crítico do Balanço Social da empresa no ano de 2003, em seus aspectos ambientais:

\begin{tabular}{|l|l|c|c|}
\hline \multicolumn{1}{|c|}{ Área } & \multicolumn{1}{|c|}{ Comentário } & Avaliação \\
\hline Energia & $\begin{array}{l}\text { Segundo dados da própria empresa, houve "queda de } 6 \% \text { no volume [de vendas], afetando as } \\
\text { marcas de preços mais baixos e mais suscetíveis à concorrência desleal. O volume de vendas no } \\
\text { ano atingiu } 76,8 \text { bilhões de cigarros }(81,9 \text { bilhões em 2002)...". Dessa forma, a explicação dada } \\
\text { para o aumento no consumo de energia foi obscura. }\end{array}$ & (-) \\
\hline Materiais & $\begin{array}{l}\text { Embora não tenha mostrado evolução do ano de 2002 para o de 2003, o desempenho acumu- } \\
\text { lado nos anos anteriores é extremamente positivo, já que aponta uma redução expressiva da } \\
\text { utilização de agrotóxicos nos cultivares de fumo. }\end{array}$ & (+) \\
\hline Água & $\begin{array}{l}\text { Houve redução no consumo total de água, ainda que seja questionável o aumento da utilização } \\
\text { de água por cigarros produzidos. }\end{array}$ & (+) \\
\hline $\begin{array}{l}\text { Emissões, } \\
\text { Efluentes } \\
\text { e Rejeitos }\end{array}$ & $\begin{array}{l}\text { A emissão de gases por processo produtivo aumentou consideravelmente, embora contrabalan- } \\
\text { çada por manejo florestal; por outro lado, os índices de reciclagem e de tratamento de esgoto } \\
\text { são muito bons, cabendo, no entanto, o questionamento de porquê não é tratado 100\% do }\end{array}$ & $(+)$ \\
\hline
\end{tabular}




\begin{tabular}{|l|l|l|}
\hline Transporte & $\begin{array}{l}\text { Neste quesito a empresa apresentou uma involução não explicada, ainda mais com a retração } \\
\text { da demanda. Já que a política de utilização de frota a gás é positiva, pode-se questionar o por- } \\
\text { quê das emissões de toneladas métricas de } C O^{2} \text { haverem aumentado 28\%, revelando possíveis } \\
\text { deficiências logísticas, especialmente de terceiros envolvidos no transporte. }\end{array}$ & $(-)$ \\
\hline Fornecedores & $\begin{array}{l}\text { Os critérios de certificação do grupo BAT não são explicitados no relatório, cabendo dúvidas a } \\
\text { respeito da profundidade e adequação de seus critérios com relação à gestão ambiental. }\end{array}$ & $(-)$ \\
\hline $\begin{array}{l}\text { Produtos e } \\
\text { Serviços }\end{array}$ & $\begin{array}{l}\text { Os impactos ambientais dos produtos e serviços da empresa são documentados, conforme } \\
\text { atesta o próprio relatório. }\end{array}$ & $(+)$ \\
\hline $\begin{array}{l}\text { Uso da terra e } \\
\text { biodiversi- } \\
\text { dade }\end{array}$ & $\begin{array}{l}\text { Neste quesito, a empresa não apresenta de fato indicadores mais sólidos a respeito da preser- } \\
\text { vaça da biodiversidade. No entanto, qualquer cultivo agrícola, incluindo reflorestamento } \\
\text { para fins enéticos, implica em redução da biodiversidade na região produtiva. Contudo, dos } \\
8,337 \text { ha de terras pertencentes à companhia, uma reserva ambiental mantida pela empresa em } \\
\text { Santa Cruz do Sul ocupa apenas } 85 \text { ha, ou seja, o equivalente a 1\% do total. É necessária uma } \\
\text { ação mais contundente, expandindo as áreas de preservação ambiental. }\end{array}$ & $(-)$ \\
\hline $\begin{array}{l}\text { Legislação } \\
\text { ambiental e } \\
\text { social }\end{array}$ & $\begin{array}{l}\text { Apesar de alguns aspectos negativos evidenciados nesta análise, a empresa provou que age em } \\
\text { consonância com a legislação ambiental brasileira. }\end{array}$ & $(+)$ \\
\hline
\end{tabular}

Quadro 1- Avaliação das Ações de Gestão Ambiental da Empresa

Da análise do Quadro 1 chega-se à conclusão de que, apesar de respeitar a legislação ambiental brasileira, a empresa vem aumentando seus índices de consumo de energia e de emissão de gases que contribuem para o efeito-estufa. Outro ponto fraco é o aumento do dióxido de carbono emitido durante o processo de transporte: informações adicionais sobre as causas desse fato devem ser apuradas e divulgadas pela empresa.

\section{3- Considerações Finais}

Da pesquisa sobre variáveis de Gestão Ambiental divulgadas pela Companhia no âmbito de seus Relatórios Sociais, verifica-se que a em. presa apresenta resultados insatisfatórios em áreas-chave, tais como gasto energético e problemas com a emissão de gases na cadeia de suprimento, particularmente transporte.

No entanto, dado que a Gestão Ambiental é um processo, não um fim, é de se esperar que medidas mitigadoras ou reparadoras sejam tomadas pela empresa.

A conclusão é a de que a simples existência de políticas de gestão ambiental, ainda que sérias e comprometidas com resultados palpáveis, não garante que a empresa seja invulnerável a falhas no aspecto ambiental. No entanto, é condição necessária para a correção dessas falhas.

\section{REFERÊNCIAS BIBLIOGRÁFICAS}

ALIER, Joan Martínez; JUSMET, Jordi Roca. Economía ecológica y política ambiental. México, D. F: Programa de las Naciones Unidas para el Medio Ambiente. México, D. F: Fondo de Cultura Económica, 2000.

ALIER, Joan Martínez. Da Economia Ecológica ao ecologismo popular. Blumenau: EDIFURB, 1998. 
ALTVATER, Elmar. O preço da riqueza. São Paulo: UNESP, 1995.

BAER, Werner. A economia brasileira. 2. ed. rev. e atual. São Paulo: Nobel, 2002.

BARBIERI, José Carlos. Gestão ambiental empresarial - conceitos, modelos e instrumentos. São Paulo: Saraiva, 2004.

CALLEMBACH, Ernest. Ecologia: um guia de bolso. São Paulo: Peirópolis, 2001.

CAVAlCANTI, Clóvis (org.). Meio ambiente, desenvolvimento sustentável e políticas públicas. São Paulo: Cortez; Recife: Fundação Joaquim Nabuco, 1997.

. Desenvolvimento e natureza: estudos para uma sociedade sustentável. 4. ed. São Paulo: Cortez, 2003.

COMISSÃO MUNDIAL SOBRE O MEIO AMBIENTE E DESENVOLVIMENTO. Nosso Futuro Comum. Rio de Janeiro: Fundação Getúlio Vargas, 1988.

DEAN, Warren. A ferro e fogo: a história e a devastação da Mata Atlântica brasileira. São Paulo: Companhia das Letras, 1996.

DINIZ, Eliezer M. Crescimento, poluição e o Protocolo de Quioto: uma avaliação do caso brasileiro. São Paulo: Banco Santos/ Universidade de Oxford, 2001.

LIEMT, Gijsbert Van. The world tobacco industry: Trends and prospects. Disponível em http://www.ilo.org/public/english/dialogue/sector/papers. Acesso em: 20 set. 2007.

SOUZA CRUZ. Relatório Anual 2003. Disponível em: < http://www.souzacruz.com.br >. Acesso em: 10 out. 2005.

VEIGA, Jose Eli da. Desenvolvimento sustentável: o desafio do século XXI. Rio de Janeiro: Garamond, 2005. 